\title{
Serologic diagnosis of Helicobacter pylori in chidren and its utility - a prospective study
}

\author{
Maria Oana Sasaran', Lorena Elena Melit², Simona Mocanu ${ }^{3}$ Ecaterina Daniela Dobru ${ }^{4}$ \\ 1Pediatrics III, "George Emil Palade" University of Medicine, Pharmacy, Sciences and Technology, \\ Tg. Mures, Romania \\ ${ }^{2}$ Pediatrics I, "George Emil Palade" University of Medicine, Pharmacy, Sciences and Technology, \\ Tg. Mures, Romania \\ ${ }^{3}$ Morphopathology, County Emergency Clinical Hospital, Tg. Mures, Romania \\ ${ }^{4}$ Internal Medicine VII, "George Emil Palade" University of Medicine, Pharmacy, Sciences and \\ Technology, Tg. Mures, Romania
}

\begin{abstract}
Introduction. Helicobacter pylori, an ubiquitary spread bacterium, is one of the main ethiologic factors of gastritis and peptic ulcer in children. Several diagnostic methods of this infection have been developed, both invasive and noninvasive, with the purpose of promoting early identification of the bacterium, therefore preventing its associated complications. Serologic tests, based upon detection of circulating Helicobacter pylori antibodies, one of the first diagnostic tests used, are widely available, non-invasive, cost-efficient, but do not possess the sensibility and specificity of histology.

Objectives. Through this study, we intend to identify the usefulness of $\lg A$ and $\lg G$ antibodies measurement in the diagnosis of Helicobacter pylori, by comparison with histhopathology examination. Nevertheless, we wish to establish wheteher there is a correlation between the presence of depictable antibodies and certain changes of the gastric mucosa.

Material and methods. We conducted a retrospective study, which included 84 patients aged between 4 and 17 years, with chronic dyspeptic symptoms, who underwent an upper digestive endoscopy, accompanied by gastric biopsies. Serologic Helicobacter pylori tests were performed in each of these patients, their results being compared with the microscopic description of gastric mucosal tissue.

Results. IgA and IgG antibodies had lower sensitivity ( $50 \%$ and $81.25 \%$, respectively) and specificity $(88.88 \%$ and $81.08 \%$, respectively) than microscopic examination. Positivation of IgA antibodies, as an alone serologic response or in combination with depictable IgG antibodies was significantly corelated with chronic gastritis caused by Helicobacter pylori $(\mathrm{p}<0.001)$.

Conclusions. Serologic tests have a lower diagnostic sensibility and specificity than histhology in the case of Helicobacter pylori, according to our study. Presence of this bacteria on microscopy was associated with chronic gastritis in all cases. Therefore, this study cannot provide enough data regarding the anatomopathological modifications associated with positive serum antibodies.
\end{abstract}

Keywords: Helicobacter pylori, peptic ulcer, children, antibodies, serologic diagnosis

\section{INTRODUCTION}

Helicobacter pylori (H. pylori) is considered one of the most widespread infections in humans (1). Although its colonization of the antrum usually does not cause symptoms, $H$. pylori still has a high prevalence rate among children with low socio-economical status (2) and is one of the major causative agents of chronic gastic inflammation, peptic ulcer, pre-neoplastic con- ditions and gastric cancer $(3,4)$. Several tests have been developed for the diagnosis of the infections, both invasive and non-invasive (5). Each of them must be used depending on the clinical settings, with non-invasive tests being more cost-effective, whereas endoscopy accompanied by gastric tissue sampling being the appropriate choice in the context of alarming symptoms (6). 
Antibody-based tests have been one of the first diagnostic tests used (7). These are widely available and provide rapid results, but are not recommended in populations with low prevalences of the infection and cannot provide information regarding the moment of the exposure to the bacterium (8). However, they are preffered in patients with recent proton-pump inhibitor or antibiotic treament, as these normally need to be discontinued at least two weeks before performance of an upper digestive endoscopy due to potential disruption of proper identification of microscopic lesions or bacteria (7).

Serological tests can also be used for the screening of populations, as all circulating antibodies (IgA, $\operatorname{IgM}, \operatorname{IgG})$, specifically directed against $H$. pylori can be detected. Most of the tests used in clinical practice are based upon IgG detection (8). Their low costs have produced serological empiric testing at large scales. Immunoglobulin $\mathrm{G}(\mathrm{IgG})$ antibodies are positive in the vast majority of patients who have contracted an $\mathrm{H}$. pylori infection, according to the literature (9). It is, however acknowledged that these types of antibodies cannot identify an active, chronic or past infection (10). A few past studies seem, however to underline the more important role of identifying $\operatorname{IgA}$ specific antibodies, which seem to be associated with active $H$. pylori infection in more than two thirds of peptic ulcer cases (11). However, significant, isolated IgA antibody production has also been reported in healthy populations, with up to $54 \%$ of cases reported after screening of a pediatric, Saudi Arabian population (3). As both types of antibodies (IgA, IgG) seem to arrouse in asymptomatic subjects, it is unsurpringly why the recent "Joint ESPGHAN/NASPGHAN Guidelines for the Management of Helicobacter pylori in Children and Adolescents" recommend against performing serological tests for diagnosis of active infection or treatment follow-up (12).

The aim of this study is to identify the utility of serum IgA and IgG antibody detection in the diagnosis of H. pylori infection, as compared to the histhopathology examination. Nevertheless, we wish to establish whether there is a correlation between the presence of circulating IgA levels, alone or in combination with depictable IgG antibodies, and certain microcopic changes of the gastric mucosa.

\section{MATERIAL AND METHODS}

We performed a prospective study on 84 patients with chronic dyspeptic symptoms, with ages between 4 and 17 years, who were admitted in Pediatrics Clinic I, from Tg. Mures Emergency County Hospital, Romania. Subjects with symptoms such as abdominal/ epigastric pain, nausea, vomiting, inapetence, pyrosis, bloating and weight defficit were enroled in the study, between February 2018 and November 2019. Serum $\operatorname{IgA}$ and $\operatorname{IgG~H}$. pylori antibodies were determined in each of the patients by enzyme linked immunosorbent assay (ELISA), before undergoing an upper digestive endoscopy (with the help of Olympus gastroscope GIF P30), accompanied by gastric biopsies- at least two pieces, taken from the gastric antrum and corpus. Microscopic examination of the gastric tissue fragments was afterwards conducted, also using Giemsa staining, in order to identify a possible $H$. pylori infection. Results of serum tests were afterwards compared with the microscopical findings.

GraphPad PrismT software was used for statistical analysis. Chi square test helped determine a possible correlation between qualitative variables. Spearman non-parametric test was used to assess correlation between the binary variables (positive/negative $H$. $p y$ lori antibodies and H. pylori status upon microscopy). The p-value had a significance treshold of 0.05 (for a confidence interval CI of 95\%).

Sensitivity was calculated by dividing the number of histologically confirmed cases of $H$. pylori infection in patients with positive IgA antibodies to the total number of $H$. pylori infected patients, whereas specificity resulted from the ratio between the number of subjects with negative IgA antibodies, the lack of $H$. pylori infection being confirmed by histology and the total number of $H$. pylori negative patients.

This research was performed in accordance with the principles of the declaration of Helsinki. The study protocol has been approved by the Ethics Committee of the University of Medicine, Pharmacy, Science and Technology "George Emil Palade" of Tg. Mures (No 64/2018 and No 507/2019). Only patients whose legal guardians signed the informed consent for participation in the study were included.

\section{RESULTS}

Mean age of patients included in the study was $12.82 \pm 3.13 \mathrm{SD}$. Out of the 84 patients enroled in the study, $H$. pylori infection was confirmed histhologically in $16(19.04 \%)$ of them. Figure 1 illustrates the gender distribution of the study group, with a femalemale ratio of 1.27:1.

A similar, almost equal distribution between the two sexes can be observed when dividing the patients into two groups, depending on the presence of $H$. $p y$ lori (figure 2).

Gender does not seem to affect the development of the infection $(p=0.7592, O R=1.39, C I=95 \%)$. Figure 3 shows the study population's background distri- 


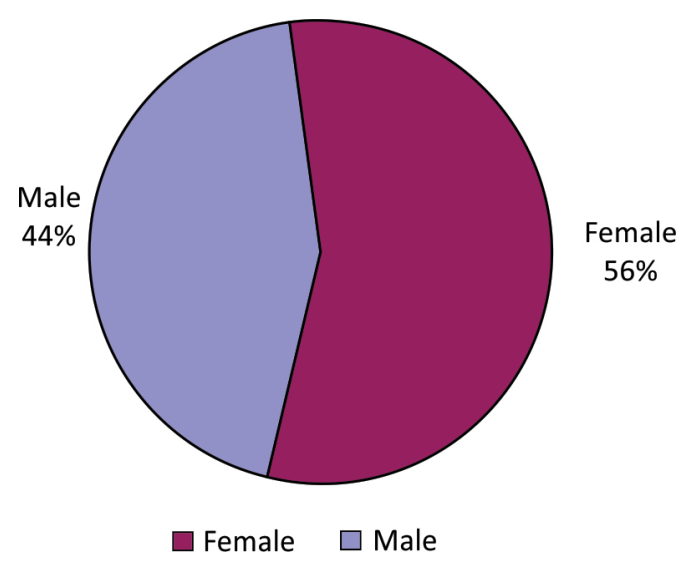

FIGURE 1. Gender distribution of the study group

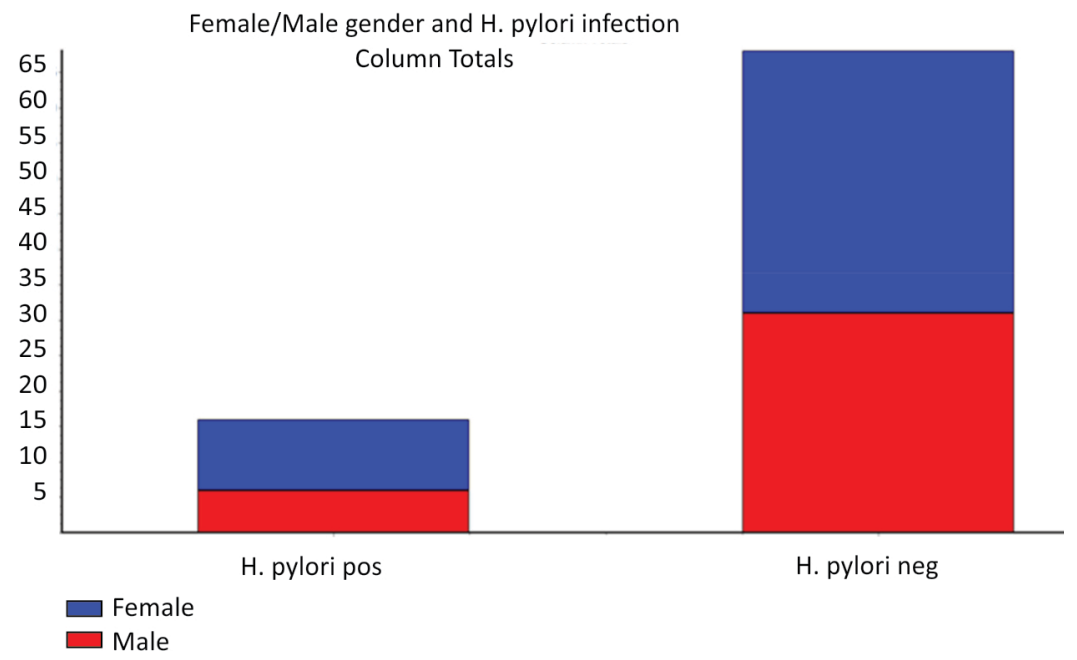

FIGURE 2. Gender distribution of the study group depending on H. pylori infection status

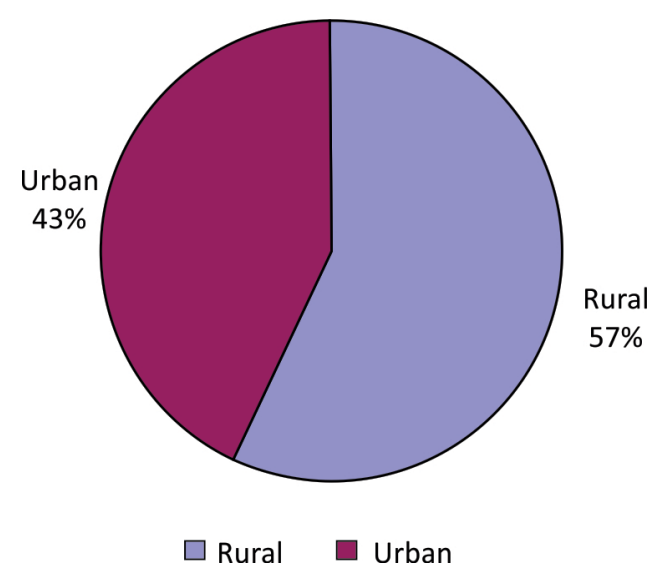

FIGURE 3. Urban/rural background of the study group

bution, while figure 4 depicts the relationship between the rural/urban background and the presence of $H$. pylori infection.

An absolute predominance of patients from rural areas can be seen in the category of those with histo- logically confirmed $H$. pylori. Nevertheless, rural environment has been positively associated with the risk of developing $H$. pylori infection $(\mathrm{p}=0.002, \mathrm{OR}=$ $15.909, \mathrm{CI}=95 \%$ ).

IgA antibodies were positive in only half of patients with $H$. pylori infection, whereas their IgG counterparts were positive in $13(81.25 \%)$ of them. Diagnostic sensitivity of IgA antibodies (as compared with microscopy) was $50 \%$, whereas specificity was $88.88 \%$. The same parameters were calculated for Ig $\mathrm{G}$ antibodies, obtaining a higher sensitivity $(81.25 \%)$, but a lower specificity $(81.08 \%)$ as in the case of $\operatorname{IgA}$. An isolated IgA response was found in only 3 (3.57\%) patients, $H$. pylori infection being confirmed in only one of them.

In terms of morphopathogy aspects, positive IgA antibodies proved to be significantly associated with chronic gastritis - figure 5 ( $\mathrm{p}<0.001, \mathrm{OR}=16.36$, CI $=95 \%)$, but not with acute inflammation of the gastric mucosa $(p=0.93, C I=95 \%)$. 


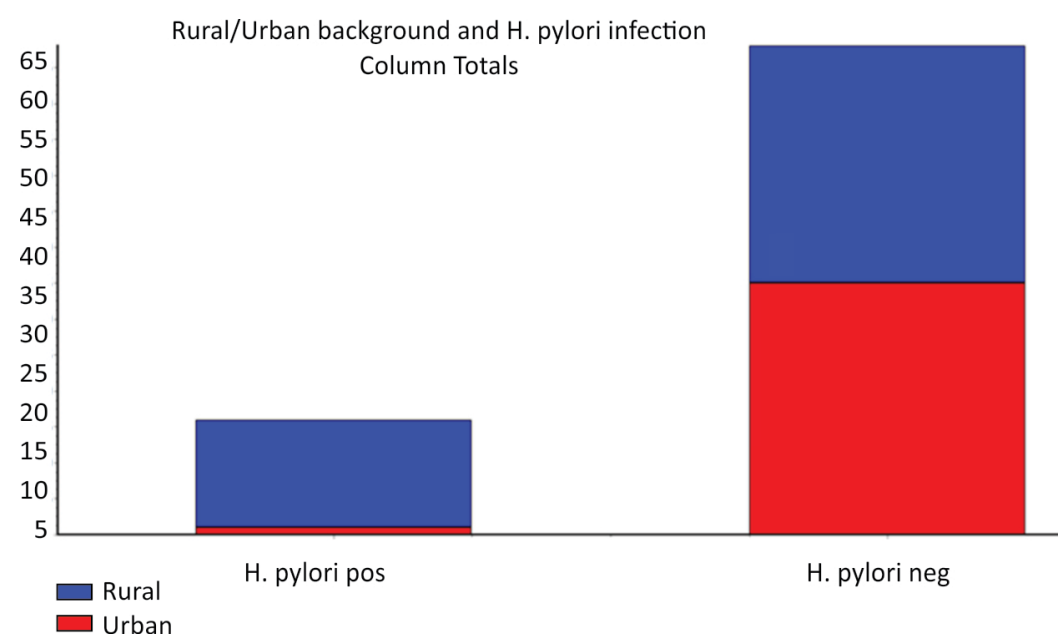

FIGURE 4. Rural/urban background distribution depending on the presence/ absence of $H$. pylori infection

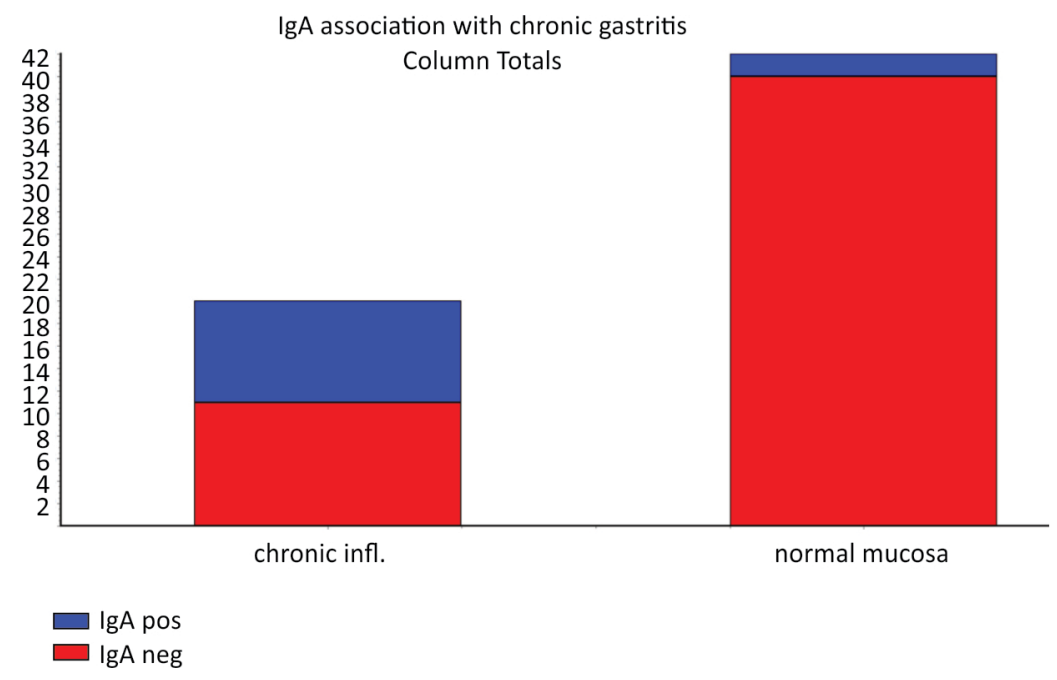

FIGURE 5. The relationship between positive/negative $\lg A$ and chronic inflammatory modifications of the gastric mucosa versus normal histhologic findings

$81.08 \%$ of chronic gastritis patients with positive IgA antibodies also had a confirmed $H$. pylori infection. Simultaneous, both positive IgA and IgG antibodies turned out to be predictors of chronic gastritis caused by $H$. pylori in all of the cases. It is important however to mention that all of the patients with identifiable $H$. pylori on microscopic assessment of the gastric tissue also presented chronic inflammatory modifications.

\section{DISCUSSIONS}

There are several studies which support the role of serum antibodies measurement, as their titers can be linked to the pathogenesis of $H$. pylori infection. Production of increased levels of IgA and IgG directed against the bacterium is related to its virulence factors, one of which being the CagA antigen, with its well known role in promoting oncogenesis (13). In spite of being related to dyspepsia, presence of the antigen does not necessarily imply that that particular strain has the capacity to secrete the CagA protein, as well $(14,15)$. Data in the literature support the existence of a relationship between the presence of IgG or IgA antibodies directed against the whole cell $H$. $p y$ lori antigen and the same type of antibodies produced against the CagA antigen (16). However, a study performed in Finland over a timespan of 21 years strongly supported the use of IgG as an universal antibody against the whole cell antigen, as this type of specific immunoglobuline is more frequently produced than $\mathrm{IgA}$ and is also correlated with IgG responses to CagA 
antigen (17). In spite of investigating only antibodies directed against the whole cell antigen, our study shows a higher percentage of IgG production in patients with $H$. pylori infection as opposed to IgA, supporting the findings of the previously mentioned study. The use of these IgG antibodies is however limited, as they cannot reflect the status of the infection and remain positive for a long time after erradication of the bacterium (18).

Interestingly, we obtained a lower sensitivity of IgA than most literature data cites. It is, though, wellknown that these parameters vary greatly depending on the performance of the detection method used (19). Sensitivity of serological diagnosis was proven to be higher with age increase (20), therefore explaining why sensitivity of serum antibodies tests in our study was far from percentages exceeding $90 \%$, reported using specific kits, only in adult patients (21).

The importance of IgA production in the defence against H.pylori, was investigated by Magen et al., in a study which involved a population with selective IgA deficiency. The authors highlighted the higher incidence of complications related to H.pylori in these patients. Nevertheless, they imply that mucosal response is not related to serum IgA or IgG antibody levels, the levels of serum IgA being dependent upon the activity of regulatory $\mathrm{T}$ cells. Therefore, they question the sole implications of IgA specific antibodies in the pathogenesis of $H$. pylori- related gastrointestinal conditions, suggesting that a malfunction of the regulatory $\mathrm{T}$ cells-IgA pathway may be involved in this process, requiring further investigation (22). This might explain why an isolated IgA serum response has been documented only in low percentages in most of the studies involving children, with $4.9 \%$ in a population from Serbia (23). A similar percentage was obtained in our study sample.

Probably the main limitation of this study is the low number of subjects and the even smaller sample

\section{REFERENCES}

1. Atherton JC, Blaser MJ. Coadaptation of Helicobacter pylori and humans: Ancient history, modern implications. J Clin Invest. 2009 Sep;119 (9):2475-87.

2. Eusebi LH, Zagari RM, Bazzoli F. Epidemiology of Helicobacter pylori infection. Helicobacter. 2014 Sep;19 Suppl 1:1-5.

3. Al-Hussaini AA, Al Jurayyan AN, Bashir SM, Alshahrani D. Where are we today with Helicobacter pylori infection among healthy children in Saudi Arabia? Saudi J Gastroenterol. 2019 Oct;25 (5):309-18.

4. Yilmaz O, Sen N, Küpelioğlu AA, Simşek I. Detection of H. pylori infection by ELISA and Western blot techniques and evaluation of anti CagA seropositivity in adult Turkish dyspeptic patients. World J Gastroenterol. 2006 Sep 7;12 (33):5375-8.

5. Wang Y-K, Kuo F-C, Liu C-J, Wu M-C, Shih H-Y, Wang SS et al. Diagnosis of Helicobacter pylori infection: Current options and developments. World J Gastroenterol. 2015 Oct 28;21 (40):11221-35. of subjects with $H$. pylori infection. Moreover, only antibodies directed against the whole cell antigen were subjects of the current study. An interesting finding is the fact that only chronic modifications of the gastric mucosa were found in relation to $H$. pylori. This explains the positive correlation between IgA secretion and chronic gastritis and the lack of association with acute inflammatory changes in the gastric mucosa, but does not provide any data regarding antibody response in cases of acute gastritis induced by H. pylori. Research data support the existence of significant, positive $\operatorname{IgA}$ and $\operatorname{IgG}$ reaction in the context of both chronic and active gastritis with $H$. pylori $(10,13)$, underlining that these types of serum responses cannot be used to predict the degree of microscopic alterations of the mucosa.

\section{CONCLUSIONS}

Serum antibodies directed against $H$. pylori have a lower diagnostic sensitivity and specificity than histology, according to our study. However, they can be used for screening puposes, for diagnosis in conjunction with an upper digestive endoscopy which involves gastric biopsies or alone, as a better option in pre-treated cases. As the infection was associated with chronic gastritis in all cases, the current study cannot provide an insight regarding the predictory value of H. pylori serum antibodies in identifying certain degrees of inflammatory alterations of the mucosa.

\section{Acknowledgement}

This article benefitted from the support of the internal research grant "The role of genomic and inflammatory markers in the determinism of child's gastritis" no. 615/11/17.01.2019., of the University of Medicine, Pharmacy, Sciences and Technology "George Emil Palade" of Tg. Mures, Romania.

\section{Conflict of interest: none declared}

6. Atkinson NSS, Braden B. Helicobacter pylori Infection: Diagnostic Strategies in Primary Diagnosis and After Therapy. Dig Dis Sci. 2016 Jan;61 (1):19-24

7. Lopes Al, Vale FF, Oleastro M. Helicobacter pylori infection - recent developments in diagnosis. World J Gastroenterol. 2014 Jul 28;20 (28):9299-313.

8. Stefano K, Rosalia A, Chiara B, Federica G, Marco M, Gioacchino L, et al. Non-invasive tests for the diagnosis of Helicobacter pylori: State of the art. Acta Biomed. 2018;89 (Suppl 8):58-64.

9. Schumann C, Triantafilou K, Rasche FM, Möricke A, Vogt K, Triantafilou M et al. Serum antibody positivity for distinct Helicobacter pylori antigens in benign and malignant gastroduodenal disease. Int $J$ Med Microbiol. 2006 Aug;296 (4-5):223-8.

10. Chen T-S, Li F-Y, Chang F-Y, Lee S-D. Immunoglobulin G antibody against Helicobacter pylori: Clinical implications of levels found in serum. Clin Diagn Lab Immunol. 2002 Sep;9 (5):1044-8. 
11. Granberg C, Mansikka A, Lehtonen OP, Kujari H, Grönfors R, Nurmi H et al. Diagnosis of Helicobacter pylori infection by using pyloriset EIA-G and EIA-A for detection of serum immunoglobulin $\mathrm{G}(\mathrm{lgG})$ and IgA antibodies. J Clin Microbiol. 1993 Jun;31 (6):1450-3.

12. Jones NL, Koletzko S, Goodman K, Bontems P, Cadranel S, Casswall T et al. Joint ESPGHAN/NASPGHAN Guidelines for the Management of Helicobacter pylori in Children and Adolescents (Update 2016). J Pediatr Gastroenterol Nutr. 2017;64 (6):991-1003.

13. Seo J-H, Lim CW, Park JS, Yeom JS, Lim J-Y, Jun J-S et al. Correlations between the CagA Antigen and Serum Levels of Anti-Helicobacter pylori IgG and IgA in Children. J Korean Med Sci. 2016 Mar;31 (3):417-22.

14. Lepper PM, Möricke A, Vogt K, Bode G, Trautmann M. Comparison of different criteria for interpretation of immunoglobulin $\mathrm{G}$ immunoblotting results for diagnosis of Helicobacter pylori infection. Clin Diagn Lab Immunol. 2004 May;11 (3):569-76.

15. Azuma T, Yamazaki S, Yamakawa A, Ohtani M, Muramatsu A, Suto H et al. Association between diversity in the Src homology 2 domain containing tyrosine phosphatase binding site of Helicobacter pylori CagA protein and gastric atrophy and cancer. J Infect Dis. $2004 \mathrm{Mar}$ 1;189 (5):820-7.

16. Suarez G, Reyes VE, Beswick EJ. Immune response to H. pylori. World J Gastroenterol. 2006 Sep 21;12 (35):5593-8.

17. Perez-Perez GI, Maw AM, Feingold-Link L, Gunn J, Bowers AL, Minano $C$ et al. Longitudinal analysis of serological responses of adults to Helicobacter pylori antigens. J Infect Dis. 2010 Sep 15;202 (6):916-23.

18. Malfertheiner P, Megraud F, O'Morain CA, Atherton J, Axon ATR, Bazzoli F et al. Management of Helicobacter pylori infection - the Maastricht IV/ Florence Consensus Report. Gut. 2012 May; 61 (5):646-64.

19. Burucoa C, Delchier J-C, Courillon-Mallet A, de Korwin J-D, Mégraud F, Zerbib F et al. Comparative evaluation of 29 commercial Helicobacter pylori serological kits. Helicobacter. 2013 Jun;18 (3):169-79.

20. Chen TS, Chang FY, Lee SD. Extending the reading time increases the accuracy of rapid whole blood test for diagnosis of Helicobacter pylori infection. J Gastroenterol Hepatol. 2001 Dec;16 (12):1341-5.

21. Kullavanijaya $P$, Thong-Ngam D, Hanvivatvong $O$, Nunthapisud $P$, Tangkijvanich P, Suwanagool P. Analysis of eight different methods for the detection of Helicobacter pylori infection in patients with dyspepsia. J Gastroenterol Hepatol. 2004 Dec;19 (12):1392-6.

22. Magen E, Waitman D-A, Goldstein N, Schlesinger M, Dickstein Y, Kahan NR. Helicobacter pylori infection in patients with selective immunoglobulin a deficiency. Clin Exp Immunol. 2016 Jun;184 (3):332-7.

23. Dinić M, Tasić G, Stanković-Dordević D, Otasević L, Tasić M, Karanikolic A. Serum anti-Helicobacter pylori IgA and IgG antibodies in asymptomatic children in Serbia. Scand J Infect Dis. 2007;39 (4):303-7. 